\title{
Getting to the heart of the matter: diagnostic tools and therapeutic approach to cardiac involvement in Behçet syndrome A Tunisian case series
}

\author{
A.S. Hammami ${ }^{1}, 2$, M. Jellazi ${ }^{1}$, S. Arfa ${ }^{1}$, S. Daada ${ }^{1}$, K. Ben Hamda ${ }^{3}$, \\ A. Achour ${ }^{4}$, S. Ouali ${ }^{1,2}$ \\ 'Department of Internal Medicine, Geriatric Unit, Hospital Fattouma Bourguiba of Monastir, Monastir, Tunisia; \\ 2Biochemistry Laboratory, LR12ES05 LR-NAFS Nutrition - Functional Food \& Vascular Health, \\ Faculty of Medicine, University of Monastir, Monastir, Tunisia; ${ }^{3}$ Department of Cardiology, Hospital Fattouma \\ Bourguiba of Monastir, Monastir, Tunisia; ${ }^{4}$ Department of Radiology, Hospital Fattouma Bourguiba \\ of Monastir, Monastir, Tunisia
}

\section{SUMMARY}

The aim was to investigate the frequency and spectrum of cardiac involvement (CI) in patients with Behçet syndrome (BS) in the Tunisian context, and to assess the clinical and imaging features, treatment, and outcomes. We retrospectively retrieved the medical records of patients with CI among 220 BS patients admitted to the hospital internal medicine department between February 2006 and April 2019, who fulfilled the International Study Group diagnostic criteria for BS.

Ten patients ( 8 men, 2 women) were eligible for the study. Mean age was 37.3 years. Three patients had 2 isolated episodes of cardiac BS. The different types of CI were coronary artery disease $(5 / 10)$, intracardiac thrombus (4/10), pericarditis (1/10), myocarditis (1/10), and myocardial fibrosis (1/10). Five patients had associated vascular involvement (50\%). Medical treatment was based on corticosteroids and colchicine in all patients (100\%), anticoagulants in 8 (80\%), and cyclophosphamide followed by azathioprine in $9(90 \%)$. The clinical course was favorable in 9 patients; 1 patient died.

CI remains an important feature of BS because of its association with increased risk of mortality and morbidity. Therefore, early screening and detection with imaging methods are paramount. Also, better cooperation between rheumatologists and cardiologists could improve outcomes.

Key words: Behçet syndrome, cardiovascular system, coronary artery disease, myocarditis, immunosuppressive agents.

Reumatismo, 2021; 73 (1): 32-43

Corresponding author: Ahmed Sami Hammami Department of Internal Medicine Fattouma Bourguiba University Hospital, Monastir, Tunisia

E-mail: hammamiahmedsami@gmail.com

\section{BACKGROUND}

ehçet's syndrome (BS) is an idiopathic, chronic, multisystemic vasculitis of unknown etiology, characterized by a remitting-relapsing course and a wide spectrum of clinical manifestations (1). It is more common and often more severe along the historic Silk Road (from Eastern Asia to the Mediterranean region). Mean age of onset is between 20 and 40 years (2). The prevalence in males and females varies among regions, but the incidence is usually higher in males $(3,4)$.

Vascular involvement is the hallmark of BS. It affects arteries and veins of different caliber, and is reported in more than $40 \%$ of patients with BS. Cardiac involvement (CI) is a rare and potentially fatal complication. The types of CI reported to date include pericarditis ( $1.6 \%$ of patients), intracardiac thrombi ( $2 \%$ of patients), coronary artery disease ( $0.5 \%$ of patients), active valvulitis $(<2 \%$ of patients) and myocarditis $(<0.5 \%$ of patients) (5-10).

Given the potential mortality and morbidity of cardiac manifestations and the lack of a well-codified treatment protocol (11), a better understanding is needed of their clinical characteristics, severity, and management. The aim of this study was to investigate the prevalence, clinical spectrum, 
imaging features, treatment, and outcomes in patients with $\mathrm{BS}$ who also had $\mathrm{CI}$ in the North African region.

\section{PATIENTS AND METHODS}

This study was approved by the institutional committee of Fattouma Bourguiba University Hospital in accordance with the ethical standards of the Declaration of Helsinki. We conducted a single-site, retrospective study based on a sample of 220 patients with BS admitted to the internal medicine department of Fattouma Bourguiba University Hospital between February 2006 and April 2016.

The inclusion criteria were (a) patients who fulfilled the International Study Group (ISG) criteria for BS (12), and (b) patients who were symptomatic at presentation (i.e. if at least 1 of the following symptoms was present: chest pain, palpitations, dyspnea, pericardial friction rub, heart murmur, or symptoms of right/left cardiac failure) and had CI classified according to the type of lesion: pericarditis, myocarditis, endomyocardial fibrosis, intracardiac thrombus, or myocardial infarction. Cardiac involvement was considered to be related to BS, if it was concomitant with BS flares. We excluded patients who did not fulfill the ISG criteria for BS, and those who had other known causes of cardiac disease. Cardiac involvement was mainly diagnosed based on clinical grounds, and on electrocardiographic and imaging techniques including echocardiography, chest computed tomography, cardiac magnetic resonance imaging, and percutaneous coronary angiography. Pathology investigations were also helpful in highlighting some specific manifestations.

Baseline demographic data and detailed clinical and laboratory data were collected from each patient's standard hospitalization documentation and medical records. Outcomes were evaluated for each patient and were classified as complete remission, partial remission, or death. Complete remission was considered as the absence of symptoms or cardiac lesions after therapy; partial remission was defined as persistent cardiac lesion with or without relapse despite treatment.
Table I - Demographic characteristics and criteria for Behçet syndrome.

\begin{tabular}{|l|c|}
\hline Parameters & All patients, $\mathrm{n}=10$ \\
\hline Gender (male/female) & $8 / 2$ \\
Mean time since the diagnosis of cardiac involvement (years) & $2.3($ range 1-9) \\
Clinical features: & \\
Recurrent oral ulcer (\%) & $10(100 \%)$ \\
Genital ulcer (\%) & $7(70 \%)$ \\
Skin lesions (\%) & $6(60 \%)$ \\
Eye involvement (\%) & $5(50 \%)$ \\
Positive pathergy test (\%) & $3(30 \%)$ \\
Articular involvement (\%) & $3(30 \%)$ \\
Arterial involvement (\%) & $3(30 \%)$ \\
Venous involvement (\%) & $3(30 \%)$ \\
Gastrointestinal involvement (\%) & $2(20 \%)$ \\
\hline
\end{tabular}

\section{RESULTS}

\section{Baseline characteristics of 10 patients with cardiac involvement}

The main characteristics of the patients selected in our study are summarized in Table I. Patients were mostly male $(80 \%)$, and mean age was 37.3 (range 20-49) years. Three of them had two episodes of cardiac BS. Cardiac involvement was the main manifestation of BS in three patients: one patient was diagnosed retrospectively after an intracardiac thrombus (ICT) was found, whereas coronary artery disease (CAD) was the initial presentation in the other two patients. In 7 patients, CI appeared during the course of the disease, up to 2.3 (range 1-9) years after the onset of BS.

\section{Cardiac lesions}

The characteristics of cardiac lesions, treatments and outcomes in patients with BS are summarized in Table II. The different types of CI were CAD (5/10) (one patient presented two episodes), ICT (4/10), myocarditis $(1 / 10)$, pericarditis $(1 / 10)$, and myocardial fibrosis (1/10). The main symptoms were chest pain $(80 \%)$, tachycardia $(60 \%)$, fever $(60 \%)$, and dyspnea $(50 \%)$. One patient with ICT associated with pulmonary embolism presented with symptoms of cough $(10 \%)$ and hemoptysis (10\%), while another had syncope $(10 \%)$. Cardiac murmur was found in 3 patients (30\%), and superior vena cava syndrome in $1(10 \%)$. Two patients presented with heart failure symptoms (20\%). Clinical examination also revealed an active 
Table II - Characteristics of lesions, treatment and outcomes in patients with Behçet syndrome and cardiac involvement.

\begin{tabular}{|c|c|c|c|c|c|c|c|}
\hline Case & Gender & $\begin{array}{c}\text { Age at } \mathrm{Cl} \\
\text { diagnosis (years) }\end{array}$ & Cardiac lesion & Vascular involvement & Treatment & $\begin{array}{c}\begin{array}{c}\text { Follow-up } \\
\text { (years) }\end{array} \\
\end{array}$ & Outcome \\
\hline 1 & Male & 33 & Myocarditis & None associated & $\begin{array}{l}\text { Colchicine, CS, } \\
\text { IS, Antiplatelet }\end{array}$ & 2 & $\begin{array}{l}\text { Complete } \\
\text { remission }\end{array}$ \\
\hline \multirow[t]{2}{*}{2} & \multirow[t]{2}{*}{ Male } & 29 & $\begin{array}{l}\text { Cardiac } \\
\text { thrombosis }\end{array}$ & \multirow[t]{2}{*}{$\begin{array}{l}\text { Inferior vena cava thrombus, } \\
\text { pulmonary embolism }\end{array}$} & $\begin{array}{l}\text { IS, Colchicine, } \\
\text { CS, AC }\end{array}$ & 10 & $\begin{array}{l}\text { Partial } \\
\text { remission }\end{array}$ \\
\hline & & 39 & $\begin{array}{l}\text { Coronary } \\
\text { stenosis }\end{array}$ & & $\begin{array}{l}\text { Colchicine, CS, } \\
\text { AC, IS, PTCA }\end{array}$ & 4 & $\begin{array}{l}\text { Partial } \\
\text { remission }\end{array}$ \\
\hline \multirow[t]{2}{*}{3} & \multirow[t]{2}{*}{ Male } & 20 & Pericarditis & \multirow{2}{*}{$\begin{array}{l}\text { Pulmonary embolism and } \\
\text { aneurysm, cerebral thrombosis, } \\
\text { superior vena cava thrombus, } \\
\text { occlusion of the right } \\
\text { brachiocephalic artery }\end{array}$} & $\begin{array}{l}\text { NSAIDs, } \\
\text { Colchicine, CS }\end{array}$ & 1 & $\begin{array}{l}\text { Complete } \\
\text { remission }\end{array}$ \\
\hline & & 21 & $\begin{array}{l}\text { Cardiac } \\
\text { thrombosis }\end{array}$ & & $\begin{array}{l}\text { AC, Colchicine, } \\
\text { CS, IS }\end{array}$ & 13 & $\begin{array}{l}\text { Complete } \\
\text { remission }\end{array}$ \\
\hline 4 & Female & 47 & $\begin{array}{l}\text { Cardiac } \\
\text { thrombosis }\end{array}$ & None associated & $\begin{array}{l}\text { AC, CS, IS, } \\
\text { Colchicine }\end{array}$ & 10 & $\begin{array}{l}\text { Complete } \\
\text { remission }\end{array}$ \\
\hline \multirow[t]{2}{*}{5} & \multirow[t]{2}{*}{ Male } & 37 & $\begin{array}{l}\text { Coronary } \\
\text { aneurysm }\end{array}$ & \multirow[t]{2}{*}{ None associated } & $\begin{array}{l}\text { CS, IS, } \\
\text { Colchicine }\end{array}$ & 2 & $\begin{array}{l}\text { Partial } \\
\text { remission }\end{array}$ \\
\hline & & 39 & $\begin{array}{l}\text { Coronary } \\
\text { stenosis }\end{array}$ & & $\begin{array}{l}\text { CS, PTCA, AC, } \\
\text { IS, Colchicine }\end{array}$ & 13 & $\begin{array}{l}\text { Complete } \\
\text { remission }\end{array}$ \\
\hline 6 & Female & 34 & $\begin{array}{l}\text { Cardiac } \\
\text { thrombosis }\end{array}$ & $\begin{array}{l}\text { Deep venous thrombosis (lower } \\
\text { limb) }\end{array}$ & $\begin{array}{l}\text { AC, CS, IS, } \\
\text { Colchicine }\end{array}$ & 3 & $\begin{array}{l}\text { Complete } \\
\text { remission }\end{array}$ \\
\hline 7 & Male & 39 & $\begin{array}{l}\text { Endomyocardial } \\
\text { fibrosis }\end{array}$ & $\begin{array}{l}\text { Superior mesenteric artery } \\
\text { aneurysm }\end{array}$ & $\begin{array}{c}\text { ATB, CS, IS AC, } \\
\text { Antiplatelet, } \\
\text { Colchicine } \\
\end{array}$ & 1 & Death \\
\hline 8 & Male & 49 & $\begin{array}{l}\text { Coronary } \\
\text { stenosis }\end{array}$ & None associated & $\begin{array}{c}\text { CS, IS, } \\
\text { Colchicine, PTCA }\end{array}$ & 2 & $\begin{array}{l}\text { Partial } \\
\text { remission }\end{array}$ \\
\hline 9 & Male & 43 & $\begin{array}{l}\text { Coronary } \\
\text { stenosis }\end{array}$ & None associated & $\begin{array}{c}\text { CS, IS, } \\
\text { Colchicine, PTCA }\end{array}$ & 16 & $\begin{array}{l}\text { Complete } \\
\text { remission }\end{array}$ \\
\hline 10 & Male & 42 & $\begin{array}{l}\text { Coronary } \\
\text { stenosis and } \\
\text { aneurysm }\end{array}$ & $\begin{array}{l}\text { Occlusion of the right } \\
\text { brachiocephalic artery }\end{array}$ & $\begin{array}{l}\text { CS, IS, } \\
\text { Colchicine, } \\
\text { CABG }\end{array}$ & 2 & $\begin{array}{l}\text { Complete } \\
\text { remission }\end{array}$ \\
\hline
\end{tabular}

ATB, antibiotics; CS, corticosteroids; IS, immunosuppressants; AC, anticoagulants; NSAIDs, non-steroid anti-inflammatory drugs; PTCA, percutaneous transluminal coronary angioplasty; CABG, coronary artery bypass grafting.

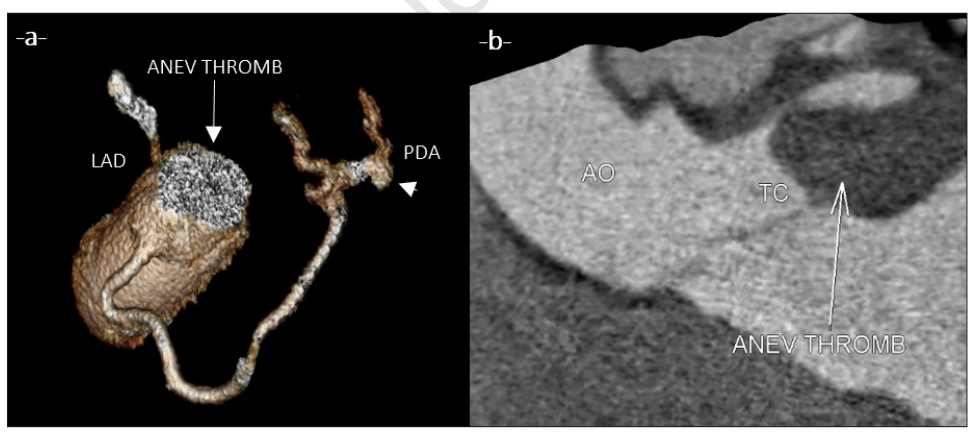

Figure 1 - Computed tomography (CT) coronary angiogram of patient number 10: (a) Three-dimensional surface-shaded display showing a giant thrombosed aneurysm in the left anterior descending artery (LAD) (arrow) associated with pre-occlusive stenosis and a posterior descending artery (PDA) aneurysm (arrowhead). (b) Oblique planar image of the aorta depicting stenosis in the left main coronary artery with thrombosis extending to the Valsalva ostium. ANEV THROMB, thrombosed aneurysm; LAD, left anterior descending artery; PDA, posterior descending artery; $\mathrm{AO}$, aorta; $\mathrm{TC}$, main left coronary artery. phase of BS, with more than one of the following symptoms: uveitis, skin lesions such as erythema nodosum, genital ulcers, oral aphthosis, arthralgia, intestinal ulceration, progressive central nervous system lesions, and progressive vasculitis. Laboratory tests revealed increased inflammatory markers in 5 patients $(50 \%)$. Coagulation profile (antiphospholipid antibodies, factor V Leiden, prothrombin mutation, and homocysteine levels) was investigated in 5 patients $(50 \%)$, and was positive in 2 of them (20\%). Anticardiolipin antibodies were positive in the patient with endomyocardial fibrosis, and an elevated homocysteine level was noted in 1 patient with ICT.

Coronary angiography was highly informative in patients who had evidence of 
CAD. Four of them had non-ST-elevation myocardial infarction, and 1 had lateral ST-elevation myocardial infarction. Smoking was the main cardiovascular risk factor in 1 patient; no other atherosclerotic risk factors were identified. Coronary artery lesions involved the right coronary artery in 2 patients, the circumflex artery in 1 patient, the left anterior descending artery in 2 patients, and the main left coronary artery in 1 patient. A large thrombosed

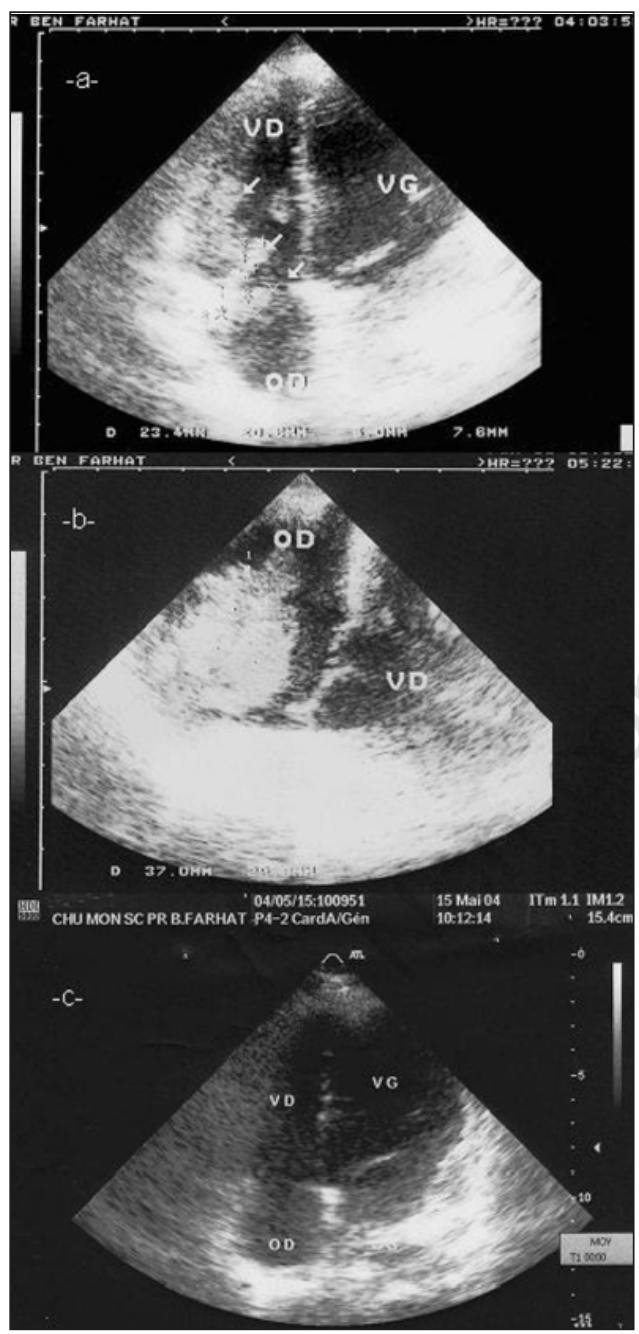

Figure 2 - Transthoracic echocardiography in patient number 3: Apical four-chamber view (VD, right ventricle; VG, left ventricle; $O D$, right atrium; $O G$, left atrium). (a) Image of a thrombus in the right atrium, and two thrombi in the right ventricle (arrows). (b) Transesophageal echocardiography showing the right atrium thrombus. (c) Complete resolution of the thrombi after treatment (58). aneurysm of the left anterior descending artery and a posterior descending artery aneurysm were identified in patient number 10 (Figure 1), and right coronary artery aneurysm was identified in patient number 5. Electrocardiography was performed in all patients, and was a key tool for CAD diagnosis. Among other incidental findings in all patients, there were left ventricular enlargement in two patients $(20 \%)$, incomplete right bundle-branch block in one patient (10\%), and premature ventricular complexes in another one (10\%).

In 4 patients, ICT was identified, and was located mostly in the right chambers of the heart $(3 / 4,75 \%)$. The diagnosis was established by transthoracic echocardiography combined with transesophageal ultrasound in 3 patients. Computed tomography was used to confirm the diagnosis of ICT as well as to scrutinize the vascular system. In patient number 3 these techniques revealed a double ICT (right atrium + ventricle) (Figure 2) associated with partial obstruction of the superior vena cava, and also disclosed pulmonary artery thrombosis and aneurysms. Right atrial thrombosis extended to the vena cava in two patients (20\%). Plasma homocysteine was elevated in patient number 2 $(27 \mu \mathrm{mol} / \mathrm{L})$.

Pericarditis was diagnosed in patient number 3 concurrently with genital and oral aphthae. Transthoracic echocardiography showed moderate pericardial effusion (10 $\mathrm{mm}$ anteriorly, $15 \mathrm{~mm}$ posteriorly).

Myocarditis was suspected in patient number 1 , who presented with pleuritic chest pain and fever. Echocardiography showed left ventricle hypokinesis, and cardiac magnetic resonance imaging confirmed the diagnosis (Figure 3).

Endomyocardial fibrosis was retrospectively identified by histological examination of the mitral valve after its replacement in patient number 7 , who was initially misdiagnosed for infective endocarditis following surgery for a superior mesenteric artery aneurysm. The same patient had positive antiphospholipid antibodies (anti-cardiolipin IgM 100 UI and IgG 7 UI) along with normal coagulation tests. 


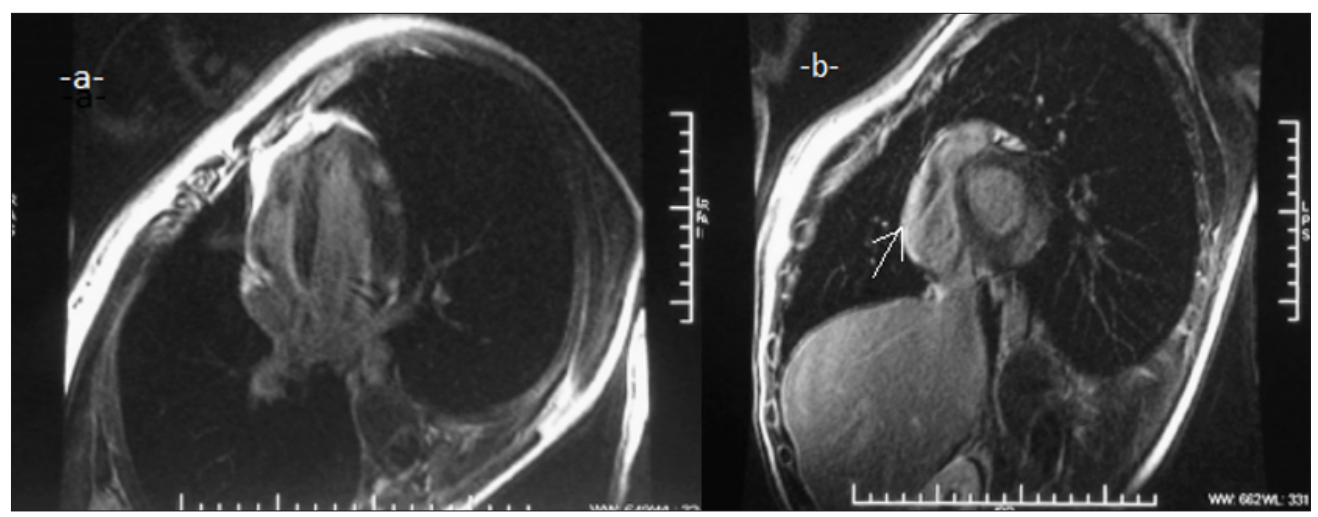

Figure 3 - Cardiovascular magnetic resonance images in two short axis views in patient number 1 with suspected myocarditis. (a) Early gadolinium enhancement anterolaterally in the subepicardial region. (b) Signal intensity increase in T2-weighted images in the anterior aspect of the heart (arrowhead).

\section{Treatment and outcomes in Behçet syndrome patients with cardiac involvement}

Medical treatment was based on colchicine $(1 \mathrm{mg} /$ day $)$ associated with corticosteroids in all patients. The regimen consisted of 3 daily intravenous pulses of methylprednisolone $1000 \mathrm{mg} /$ day followed by oral prednisone $(1 \mathrm{mg} / \mathrm{kg}$ daily), which was gradually tapered over 6 months. Six-month pulses of cyclophosphamide followed by azathioprine were administered in 9 patients $(90 \%)$. Three patients $(30 \%)$ had a second 6-month course of cyclophosphamide due to the recurrence of their CI. Azathioprine was started in one patient (10\%). All patients with BS and ICT received anticoagulants. Complete remission was obtained in 3 out of 4 patients, and the thrombus persisted in one patient. All patients with myocardial infarction benefited from coronary angiography: 3 out of 5 were successfully treated by percutaneous transluminal coronary angioplasty, and patient number 10 underwent a double coronary artery bypass grafting procedure. No complications were noted after the procedures. $\mathrm{Pa}$ tient number 5 relapsed after 2 years, with right coronary artery stenosis. Two out of 5 patients developed ischemic cardiomyopathy. Pericarditis was treated with nonsteroid anti-inflammatory drugs and corticoids. Antibiotics and surgical valve replacement were indicated in patient number 7 , who experienced severe heart failure and died despite immunosuppressive therapy. The other 9 patients are currently being monitored with regular clinical and laboratory follow-up.

\section{DISCUSSION}

Behçet syndrome is a chronic inflammatory disease of unknown origin $(1,13)$. It is characterized by recurring flares of acute inflammation marked by oral aphthae and other systemic manifestations including mucocutaneous, ocular, neurologic, gastrointestinal, and cardiovascular symptoms $(3,4)$.

Although CI remains rare in most crosssectional studies (5), this manifestation may persist long after disease activity is suppressed, and may have deleterious consequences in terms of damage accrual in the short term along with a substantial impact on morbidity in the long run (14). As reflected in the internationally developed tool to assess damage in BS, it has been increasingly recognized that $\mathrm{CI}$ is an important aspect of the course of the disease, which frequently exceeds other manifestations in mortality and morbidity rates (15). Therefore, its poor prognosis should be addressed and recognized by physicians who care for patients with BS.

The present study describes an array of cardiac manifestations, with a focus on clinical manifestations, treatments and outcomes. 
It is among the first studies in the North African region to document a particular propensity for $\mathrm{CAD}$, considered an infrequent manifestation of BS $(10,16)$. Vasculitis is the hallmark of the disease pathogenesis, and is thought to be the prime mover of cardiac lesions (17). In this connection, activated neutrophils cause excessive oxidative stress through increased levels of free radicals, such as superoxide anions, along with increased lysosomal enzymes, which eventually lead to destructive effects (18).

Cardiac involvement is a rare finding in $\mathrm{BS}$, and has been reported in $0.13 \%$ to $16.5 \%$ of patients in previous studies. This frequency varies depending on the ethnic group and geographic locations $(2,3,6,9$, 19-24) (Table III).

In the present study, mean age of patients with BS who had CI was 37.3 years, and male gender predominated $(\mathrm{M}: \mathrm{F}=4: 1)$, suggesting that the prevalence of $\mathrm{CI}$ in males is higher than the overall relative prevalence of BS in men and women (M:F $=1.3: 1)$ (25). Likewise, Wang et al. reported (3) that males accounted for $75 \%$ of all BS patients with ICT, and their mean age was 33.5 years. Hence, according to these observations, this severe manifestation of BS tends to occur more often in young adult men.

\section{Cardiac features}

Cardiac involvement may be the cardinal manifestation of BS, as was the case in $30 \%$ of our patients, a proportion in line with previous results $(3,6,26)$. Therefore, a diagnosis of cardiac BS should be consid- ered even in patients who do not show the classical criteria, particularly young male patients living in areas along the historic Silk Road.

Coronary artery involvement in BS is extremely uncommon. In fact, Ozeren et al. reported a prevalence of CAD less than $0.5 \%$ (27). Therefore, the importance of this study lies in highlighting the target population characteristics, the prognosis, and possible treatment cornerstones. As previously described, CI affects mainly young male patients without prominent atherosclerotic cardiovascular risk factors, who reside in countries traversed by the ancient Silk Road such as Turkey as well as countries in the Middle East, Mediterranean basin and parts of Asia $(14,28)$. Cardiac complications pose several diagnostic and therapeutic challenges. Indeed, the exact etiology leading to acute coronary events in patients with BS is not well known. Impaired microvascular function, arterial thrombi, and the presence of inflammation are believed to be the causes of coronary events in these patients (16). Nevertheless, there are several other etiologies that should be taken into account initially, such as primary atherosclerotic CAD, especially in adults with significant atherosclerotic risk factors, e.g. hypertension, dyslipidemia, diabetes, obesity, and smoking.

Coronary artery disease often manifests as myocardial infarction (6). The silent form hinders the diagnosis of this manifestation, which consequently is rarely reported. Indeed, $19.5 \%$ of patients with BS in a study by Turkolmez et al. had silent myocardial

Table III - Frequency of cardiac involvement in Behçet syndrome in the literature.

\begin{tabular}{|l|c|c|c|}
\hline Author (country) & Year & Number of patients with BS & Cardiac involvement frequency \\
\hline Lakhanpal (Japan) (21) & 1985 & 170 & $16.5 \%$ \\
\hline Assaad-Khalili (Egypt) (55) & 1993 & 350 & $15 \%$ \\
\hline Gurler (Turkey) (22) & 1997 & 2147 & $0.13 \%$ \\
\hline B'chir Hamzaoui (Tunisia) (23) & 2006 & 519 & $2 \%$ \\
\hline Geri (France) (6) & 2012 & 807 & $6 \%$ \\
\hline Zhang (China) (24) & 2013 & 334 & $8,1 \%$ \\
\hline Wang (China)(3) & 2016 & 626 & $1.9 \%$ \\
\hline This study & 2020 & 220 & $4.54 \%$ \\
\hline
\end{tabular}


infarction compared to $2.9 \%$ of sex- and age matched of healthy control individuals (29). Lesions affecting the coronary arteries include stenosis, occlusion, in-stent stenosis, and aneurysm, the latter of which is the primary classic lesion in BS (26). Recurrent flares of BS are also associated with CAD involvement with repeated instent stenosis, aggressive progression, and elevated inflammation markers as seen in patient number 5 , who had a recurrence of his CAD (30). Therefore, concurrent vascular involvement (e.g. patients 2 and 10) highlights the underlying vasculitis that goes hand in hand with coronary involvement (31).

We noted that $50 \%$ of patients cases had additional multifocal vascular involvement, i.e. pulmonary embolism, vena cava thrombosis, or right brachiocephalic artery occlusion. Among these patients, 2 had relapsing CI manifestations, which sometimes differed from the symptoms in their initial CI. Therefore, we emphasize that an initial cardiac event in a patient with BS is predictive of potential development of progressive multifocal vascular and cardiac complications (32).

Compared to venous thrombi, ICTs are relatively uncommon, and were reported in $1.9 \%$ of $626 \mathrm{BS}$ patients in a study by Wang et al. (3). However, they were the second most frequent cardiac complication is our series ( $40 \%$ of cases), and this can be explained by geographic influence given that the Mediterranean basin is considered an endemic area (10). Usually, ICT occurs in males older than 40 years who do not receive adequate immunosuppressive therapy within 10 years of the diagnosis (3). However, it can also be the presenting sign of BS as observed in patient number 6 in the present study. The close association between vascular involvement and ICTs in our series is indicative of an ongoing inflammatory process: endothelium-dependent flow-mediated dilation is diminished, causing an increase in vascular inflammation. This leads to endothelial dysfunction which, along with thrombin and fibrin release, triggers thromboembolism (16, 33). Additionally, hyperhomocysteinemia has been investigated in some studies as a predictor of BS activity; moreover, it may contribute to the pathogenesis of the disease, which could explain this finding in our series (20). As previously reported (2, 26), ICTs involved the right heart chambers more often than the left (3 right vs. 1 left atrial thrombus), perhaps because some thrombi have extended from the vena cava, and also because the lower pressure in the right heart predisposes toward blood flow stasis, one of the criteria in Virchow's triad. This is particularly important when considering the differential diagnosis, because heart tumors (myxomas) are frequently located in the left atrium (34). On the other hand, cardiac thrombi are also frequently misdiagnosed as infective endocarditis because of their indistinct features on echocardiography (e.g. vegetation-like lesions and echo-free spaces); hence, it is important to consider a differential diagnosis in case of an inadequate response to antibiotics along with a negative blood culture (35). Furthermore, right heart chamber thrombi are highly specific for BS $(13,36)$. Echocardiography along with computed tomography were highly informative in detecting ICTs, and the latter was also used as a screening tool for vascular involvement. In patient number 3 , for example, computed tomography revealed pulmonary arterial aneurysms and thrombosis as well as a superior vena cava thrombus. This extremely rare entity is termed Hughes-Stovin syndrome (37).

In contrast to our study, pericardial involvement was reportedly the most common manifestation of BS in French cohorts, representing respectively $40 \%$ and $38.5 \%$ of CI in the studies by Wechsler et al. and Geri et al., respectively $(6,9)$. However, $\mathrm{Pu}$ et al. analyzed the echocardiographic findings in 63 Chinese patients with BS who had cardiac involvement, and found pericarditis in only one (10). We believe that differences among studies in the frequencies of pericarditis are inherent to the geographic characteristics of BS.

Because pericarditis is primarily due to viral agents (e.g. cytomegalovirus, EpsteinBarr virus, etc.), viral serology studies are 
important in determining whether this CI should be attributed to BS (38). This complication can also be the cardinal presentation of BS, and although it may recur, it rarely leads to further complications such as constrictive pericarditis (6). Pericarditis can be symptomatic with stabbing chest pain, fever and dyspnea; in contrast, asymptomatic pericardial effusion can be detected as electrocardiographic abnormalities or with systematic echocardiography $(19,39,40)$.

Endomyocardial involvement manifests mainly as valvular dysfunction or more rarely as endomyocardial fibrosis. In valvular involvement, the aortic and mitral valves are the most frequently affected (41). Clinically, valvular involvement can appear as an isolated acute or subacute manifestation, and is usually diagnosed by echocardiography. Endomyocardial fibrosis, on the other hand, is an exceptional, yet severe complication of BS. In fact, according to a 1985 study based on the Japanese autopsy registry, among 170 autopsies of patients with BS, only 2 disclosed this cardiac lesion (21). Endomyocardial fibrosis usually presents as symptoms of right heart failure, and is diagnosed during pathology examination of biopsy specimens (as at our tertiary care center, for example). It can also be misdiagnosed as infective endocarditis. Accordingly, if the presentation is incomplete and echocardiographic findings are present, the major Duke criteria may be met, resulting in delayed diagnosis, a worse prognosis, and a possibly fatal outcome, as in our series $(10,14)$. Failure to respond to antibiotics along with evidence from pathology studies of biopsy specimens are tools that can confirm the presence of fibrosis. This manifestation has been associated with anti-cardiolipin antibodies, which may have contributed to the pathogenesis of fibrosis; however, the relevance of this association is still unknown (42).

Isolated myocarditis is rarely reported in BS, and was found in only 1 case among 807 European patients with BS in a study by Geri et al. (6). Nevertheless, the frequency of myocardial involvement may be underestimated, given that it is reported more often in studies where patients underwent systematic screening with imaging techniques such as echocardiography or scintigraphy $(10,20)$. The diagnosis should be suspected, after ruling out other causes of myocarditis (viral, giant cell myocarditis, etc.), in patients with symptoms of heart failure, conduction abnormalities, or kinetic abnormalities on ultrasound (4345). Cardiac magnetic resonance imaging has become an essential aid in diagnosing myocarditis owing to its ability to facilitate objective assessments of myocardial inflammation (46).

The aim of treatment for CI in BS is to decrease morbidity and mortality by repressing inflammation and thus preventing permanent organ damage. However, the European League Against Rheumatism (EULAR) provides limited information about $\mathrm{CI}$ in their BS management guidelines (2018 edition), and most of this document deals with its research agenda (11). Hence treatment remains mainly at the physician's discretion, and is still based on a low level of evidence $(14,19)$.

In the present study, remission of CI was associated with corticosteroids and immunosuppressive drugs, with cyclophosphamide and azathioprine being the most widely used. Nevertheless, this finding should be interpreted with caution because of the inherent differences between CIs. Treatment for CAD in the context of BS can be very challenging and often burdensome. For example, anticoagulants and thrombolytics may precipitate bleeding in aneurysms (47), and glucocorticoid pulses can curtail the heart healing process, rendering the organ more prone to rupture $(14,48)$. The cornerstone of CAD treatment remains the early implementation of anti-inflammatory agents, especially before mechanical manipulation of the coronary vessels (surgery or angioplasty), which could cause what is known as 'vascular pathergy', which can be very risky (30). Similarly, caution is needed in the management of endomyocardial involvement, particularly in the preoperative course of surgical excision (49). The prognosis of CAD is usually poor, as it can lead to ischemic cardiomyopathy or 
ventricular aneurysms and, in severe cases, to the rupture of coronary aneurysms and death (6). The combination of anticoagulants, glucocorticoids and immunosuppressants was effective in treating ICTs at our tertiary referral center. Other physicians also use remote thrombolytics for mobile clots (19). However, if the ICT is associated with a pulmonary artery aneurysm, it must be treated with intensive immunosuppressive therapy, and anticoagulants should be given cautiously because of the risk of bleeding. Transcatheter embolectomy may be beneficial in such cases $(2-4,19)$. Moderate pericarditis can be treated with nonsteroid anti-inflammatory drugs, and less frequently with immunosuppressive agents if recurrent (4). For example, colchicine, indicated in all cases of BS, has been reported to be an efficient treatment for pericarditis regardless of its etiology, even when it recurs (50). The outcome in our series was favorable; however, relapses were frequently reported in other studies (6). Myocarditis is a rare complication of $\mathrm{BS}$, and treatment is mainly focused on managing heart failure and arrhythmias, with glucocorticoids and immunosuppressants as adjuvants.

Anti-TNFo antibodies and interferonalpha have proven efficacious in patients with BS who have severe ocular involvement (i.e. panuveitis) $(51,52)$. Furthermore, the EULAR recommendations for managing BS increasingly encourage the consideration of immunologic treatments for extraocular complications refractory to immunosuppressants (e.g. neurological and vascular involvement) (11). Indeed, according to a study by Desbois et al., anti$\mathrm{TNF} \alpha$ agents represent a safe and effective therapeutic approach for patients who have BS with major vessel involvement, leading not only to a steroid-sparing effect, but also prolonging the time to relapse (53). In light of these findings, we believe that biological agents can be beneficial for refractory $\mathrm{CI}$; however, the evidence is still scarce and is mainly based on case reports (54). Therefore, future prospective studies and randomized controlled trials are required to verify the effectiveness of these treatments in the management of cardiac BS.
Overall, survival in BS patients with $\mathrm{CI}$ is unfavorable compared to patients without CI. Global 5-year mortality from BS is estimated at $5.4 \%$, and reaches $15.4 \%$ to $20 \%$ in patients with $\mathrm{CI}(5,55)$. The prognosis is better in patients who receive an earlier diagnosis, especially with the early use of anti-inflammatory drugs. We recommend that patients who are diagnosed with or suspected to have BS, particularly young males living in endemic areas, should be followed up routinely for CI. Imaging techniques such as echocardiography or angiography are potentially very helpful as screening methods for follow-up. We also propose a standardized approach based on cooperation between cardiologists and rheumatologists, in which synergistic decisions can be made that may well improve the patient's outcome.

We believe that $\mathrm{CI}$ is the result not only of an inflammatory process but also of a strong underlying genetic background in patients with BS. In recent years, it has been postulated that platelet-neutrophil complexes (PNC) may be closely connected with vascular and cardiac involvement in BS (thrombosis-inflammation-aneurysm). More prospective studies are needed to investigate this possible link, given that knowledge of the target genes may lead to new treatment approaches (56).

The limitations of our study include the small cohort due to the rarity of the disease and its retrospective nature. Prospective enrollment would have been ideal; however, this is very difficult to achieve with rare diseases. We also note that echocardiography, which may facilitate the diagnosis of asymptomatic BS in patients with CI, was used only in patients with symptomatic BS, but was not used systematically in the entire original sample of 220 patients. Moreover, all patients were enrolled from a single tertiary care center, so potential selection bias cannot be ruled out. Large prospective case-controlled studies are thus warranted to address these limitations.

Finally, despite being a rare manifestation of BS, CI remains a striking complication marked by high mortality and morbidity rates. Therefore, CI should be recog- 
nized in the early course of the disease, and treated accordingly. Nevertheless, the most widely used criteria for BS (ISG) date from 1990 (12) and do not consider specific organ involvement such as CI. In our cohort, 3 patients had $\mathrm{CI}$ as the cardinal manifestation, and their cardiac symptoms delayed the diagnosis of BS, because they did not fulfil the ISG criteria. Therefore, efforts to diagnose BS should be tailored on a case-by-case basis even when the classic diagnostic criteria are not met. The International Criteria for Behçet's disease (ICBD) 2014 criteria (57) encompass a more specific organ involvementoriented approach (e.g. vascular and neurologic involvement), and may be useful in improving the sensitivity of diagnostic criteria for BS (58).

\section{CONCLUSIONS}

Cardiac involvement, despite its rarity in $\mathrm{BS}$, is among the most severe complication of this disease. It is more often present in young males, and may affect all three cardiac tunics and the coronary arteries. Echocardiography is the major radiologic imaging techniques that can provide efficient early screening of asymptomatic patients who live in areas along the Silk Route. The prognosis for cardiac complications is worse than for any other systemic manifestation of BS. Therefore, early diagnosis and treatment are paramount to improving survival rates. We believe closer cooperation between rheumatologists and cardiologists is a potentially important contributor to better clinical management of cardiac involvement in patients with BS.

\section{Acknowledgments}

The authors acknowledge Dr. Abdulrazzak Abyad, Coordinator of the Middle-East Primary Care Research Network, and Dr. Habib Gamra, chief of the Cardiology Department, Fattouma Bourguiba Hospital, University of Monastir, for their kind advice in this field. The authors also thank $\mathrm{K}$. Shashok (AuthorAID in the Eastern Mediterranean) for improving the English text of this manuscript.

\section{Funding}

This research did not receive any specific grant from funding agencies in the public, commercial, or not-for-profit sectors.

\section{Authors' contributions}

ASH conceived this study; ASH and MJ analyzed and interpreted data, and drafted the manuscript; SD and SA contributed to data acquisition and collection; SO and $\mathrm{KBH}$ revised the manuscript. All authors read and approved the final manuscript.

\section{Conflict of interests}

The authors declare no potential conflict of interests.

\section{REFERENCES}

1. Saylan T. Life story of Dr. Hulusi Behçet. Yonsei Med J. 1997; 38: 327-32.

2. Zhu YL, Wu QJ, Guo LL, Fet al. The clinical characteristics and outcome of intracardiac thrombus and aortic valvular involvement in Behçet's disease: an analysis of 20 cases. Clin Exp Rheumatol. 2012; 30: S40-5.

3. Wang H, Guo X, Tian Z, et al. Intracardiac thrombus in patients with Behcet's disease: clinical correlates, imaging features, and outcome: a retrospective, single-center experience. Clin Rheumatol. 2016; 35: 2501-7.

4. Eren H, Öcal L, Kalçik M, et al. Intracardiac thrombus in Behçet's disease. J Cardiovasc Echogr. 2016; 26: 22-4.

5. Desbois AC, Wechsler B, Cluzel P, et al. (Cardiovascular involvement in Behçet's disease). Rev Med Interne. 2014; 35: 103-11.

6. Geri G, Wechsler B, Thi Huong du L, et al. Spectrum of cardiac lesions in Behçet disease: a series of 52 patients and review of the literature. Medicine (Baltimore). 2012; 91: 25-34.

7. Han JK, Kim HK, Kim YJ, et al. Behçet's disease as a frequently unrecognized cause of aortic regurgitation: suggestive and misleading echocardiography findings. J Am Soc Echocardiogr. 2009; 22: 1269-74.

8. Seyahi E, Ugurlu S, Cumali R, et al. Atherosclerosis in Behçet's syndrome. Semin Arthritis Rheum. 2008; 38: 1-12.

9. Wechsler B, Du LT, Kieffer E. (Cardiovascular manifestations of Behçet's disease). Ann Med Interne (Paris). 1999; 150: 542-54.

10. Pu L, Li R, Xie J, et al. Characteristic echocardiographic manifestations of Behçet's disease. Ultrasound Med Biol. 2018; 44: 825-30.

11. Hatemi G, Christensen R, Bang D, et al. 2018 update of the EULAR recommendations for 
the management of Behçet's syndrome. Ann Rheum Dis. 2018; 77: 808-18.

12. International Study Group for Behçet's Disease. Criteria for diagnosis of Behçet's disease. Lancet. 1990; 335: 1078-80.

13. Behçet H, Matteson EL. On relapsing, aphthous ulcers of the mouth, eye and genitalia caused by a virus. 1937. Clin Exp Rheumatol. 2010; 28: S2-5.

14. Farouk H, Zayed HS, El-Chilali K. Cardiac findings in patients with Behçet's disease: Facts and controversies. Anatol J Cardiol. 2016; 16: 529-33.

15. Piga M, Floris A, Espinosa G, et al. Development and preliminary validation of the Behçet's syndrome Overall Damage Index (BODI). RMD Open. 2020; 6: e001192.

16. Vural U, Kizilay M, Aglar AA. Coronary involvement in Behçet's disease: what are its risks and prognosis? (rare cases and literature review). Braz J Cardiovasc Surg. 2020; 34: 749-58.

17. Ehrlich GE. Vasculitis in Behçet's disease. Int Rev Immunol. 1997; 14: 81-8.

18. Harzallah O, Kerkeni A, Baati T, Mahjoub S. Oxidative stress: correlation with Behçet's disease duration, activity and severity. Eur J Intern Med. 2008; 19: 541-7.

19. Demirelli S, Degirmenci H, Inci S, Arisoy A. Cardiac manifestations in Behcet's disease. Intractable Rare Dis Res. 2015; 4: 70-5.

20. Kartal Durmazlar SP, Akgul A, Eskioglu F. Homocysteine may involve in the pathogenesis of Behcet's disease by inducing inflammation. Mediators Inflamm. 2008; 2008: 407972.

21. Lakhanpal S, Tani K, Lie JT, et al. Pathologic features of Behçet's syndrome: a review of Japanese autopsy registry data. Hum Pathol. 1985; 16: 790-5.

22. Gürler A, Boyvat A, Türsen U. Clinical manifestations of Behçet's disease: an analysis of 2147 patients. Yonsei Med J. 1997; 38: 423-7.

23. B'Chir Hamzaoui S, Harmel A, Bouslama K, et al. (Behçet's disease in Tunisia. Clinical study of 519 cases). Rev Med Interne. 2006; 27: 742-50.

24. Zhang Z, He F, Shi Y. Behcet's disease seen in China: analysis of 334 cases. Rheumatol Int. 2013; 33: 645-8.

25. Mahr A, Belarbi L, Wechsler B, et al. Population-based prevalence study of Behçet's disease: differences by ethnic origin and low variation by age at immigration. Arthritis Rheum. 2008; 58: 3951-9.

26. Mogulkoc N, Burgess MI, Bishop PW. Intracardiac thrombus in Behçet's disease: a systematic review. Chest. 2000; 118: 479-87.

27. Ozeren M, Mavioglu I, Dogan OV, Yucel E. Reoperation results of arterial involvement in Behçet's disease. Eur J Vasc Endovasc Surg. 2000; 20: 512-9.
28. Sokhanvar S, Karimi M, Esmaeil-Zadeh A. Recurrent acute myocardial infarction with coronary artery aneurysm in a patient with Behçet's disease: a case report. J Med Case Rep. 2009; 3: 8869 .

29. Türkölmez S, Gökçora N, Alkan M, Gorer MA. Evaluation of myocardial perfusion in patients with Behçet's disease. Ann Nucl Med. 2005; 19: 201-6.

30. Ma W, Liang Y, Zhu J. Ten-year progress of coronary artery lesions prior to Behçet disease diagnosis: A case report and care-compliant article. Medicine (Baltimore). 2017; 96: e9102.

31. Gürgün C, Ercan E, Ceyhan C, et al. Cardiovascular involvement in Behçet's disease. Jpn Heart J. 2002; 43: 389-98.

32. Kural-Seyahi E, Fresko I, Seyahi N, et al. The long-term mortality and morbidity of Behçet syndrome: a 2-decade outcome survey of 387 patients followed at a dedicated center. Medicine (Baltimore). 2003; 82: 60-76.

33. Evereklioglu C. Current concepts in the etiology and treatment of Behçet disease. Surv Ophthalmol. 2005; 50: 297-350.

34. Ghori MA, Al Sousi A, Al Mahmeed W, et al. A case report of a right ventricular mass in a patient with Behçet's disease: Myxoma or thrombus? J Saudi Heart Assoc. 2013; 25: 85-9.

35. Emmungil H, Yaşar Bilge N, Küçükşahin O, et al. A rare but serious manifestation of Behçet's disease: intracardiac thrombus in 22 patients. Clin Exp Rheumatol. 2014; 32: S87-92.

36. Saadoun D, Wechsler B. Behçet's disease. Orphanet J Rare Dis. 2012; 7: 20.

37. Khalid U, Saleem T. Hughes-Stovin syndrome. Orphanet J Rare Dis. 2011; 6: 15-.

38. Chang SA. Tuberculous and infectious pericarditis. Cardiol Clin. 2017; 35: 615-22.

39. Bletry O, Mohattane A, Wechsler B, et al. (Cardiac involvement in Behçet's disease. 12 cases). Presse Med. 1988; 17: 2388-91.

40. Kwon CM, Lee SH, Kim JH, et al. A case of Behçet's disease with pericarditis, thrombotic thrombocytopenic purpura, deep vein thrombosis and coronary artery pseudo aneurysm. Korean J Intern Med. 2006; 21: 50-6.

41. Gao N, Han W, Ci WP, et al. (Clinical data analysis of cardiovascular involvement in Behcet's disease). Zhonghua Yi Xue Za Zhi. 2016; 96: 1523-6.

42. Zivkovic M, Zlatanovic M, Zlatanovic G, et al. Anticardiolipin antibodies in patients with Behcet's disease. Bosn J Basic Med Sci. 2011; 11: 58-61.

43. Higashihara M, Mori M, Takeuchi A, et al. Myocarditis in Behcet's disease--a case report and review of the literature. J Rheumatol. 1982; 9: 630-3.

44. Okcun B, Baran T, Babalik E, Kücükoglu S. Multichamber masses and constrictive peri- 
carditis in Behçet's disease. Clin Exp Rheumatol. 2003; 21: S55.

45. Rose NR, Neumann DA, Herskowitz A. Coxsackievirus myocarditis. Adv Intern Med. 1992; 37: 411-29.

46. Friedrich MG, Sechtem U, Schulz-Menger J, et al. Cardiovascular magnetic resonance in myocarditis: A JACC White Paper. J Am Coll Cardiol. 2009; 53: 1475-87.

47. Sonia H, Khaldoun BH, Sylvia M, et al. Stenosis and aneurysm of coronary arteries in a patient with Behçet's Disease. Open Cardiovasc Med J. 2008; 2: 118-20.

48. Antman EM, Anbe DT, Armstrong PW, et al. ACC/AHA guidelines for the management of patients with ST-elevation myocardial infarction; A report of the American College of Cardiology/American Heart Association Task Force on Practice Guidelines (Committee to Revise the 1999 Guidelines for the Management of patients with acute myocardial infarction). J Am Coll Cardiol. 2004; 44: E1-e211.

49. Huong DLT, Wechsler B, Papo T, et al. Endomyocardial fibrosis in Behçet's disease. Ann Rheum Dis. 1997; 56: 205-8.

50. Imazio M, Brucato A, Cemin R, et al. Colchicine for recurrent pericarditis (CORP): a randomized trial. Ann Intern Med. 2011; 155: 409-14.

51. Sfikakis PP, Theodossiadis PG, Katsiari CG, et al. Effect of infliximab on sight-threatening panuveitis in Behçet's disease. Lancet. 2001; 358: 295-6.

52. Wechsler B, Bodaghi B, Huong DL, et al. Efficacy of interferon alfa- $2 \mathrm{a}$ in severe and refractory uveitis associated with Behçet's disease. Ocul Immunol Inflamm. 2000; 8: 293-301.

53. Desbois AC, Biard L, Addimanda O, et al. Efficacy of anti-TNF alpha in severe and refractory major vessel involvement of Behcet's disease: A multicenter observational study of 18 patients. Clin Immunol. 2018; 197: 54-9.

54. Isıyel E, Bakkaloğlu S, Oğuz D, et al. An adolescent case of extensive Behçet’s disease successfully treated with Infliximab. Turk J Pediatr. 2019; 61: 585-8.

55. Assaad-Khalil S, Sobhy M, Abou-Seif M, ElSawy M. C 37 Cardiac manifestations of Behçet's disease: clinical, genetic and echocardiographic study. Rev Méd Int. 1993; 14: 42s.

56. Pamuk GE, Pamuk ON, Orüm H, et al. Might platelet-leucocyte complexes be playing a role in major vascular involvement of Behçet's disease? A comparative study. Blood Coagul Fibrinolysis. 2010; 21: 113-7.

57. The International Criteria for Behçet's Disease (ICBD): a collaborative study of 27 countries on the sensitivity and specificity of the new criteria. J Eur Acad Dermatol Venereol. 2014; 28: 338-47.

58. Hammami S, Mahjoub S, Ben-Hamda K, et al. Intracardiac thrombus in Behçet's disease: two case reports. Thromb J. 2005; 3 : 9. 